\title{
The Treatment of Narcolepsy-Cataplexy with Nocturnal Gamma-Hydroxybutyrate
}

\author{
ROGER BROUGHTON AND MORTIMER MAMELAK
}

SUMMARY: Sixteen patients with narcolepsy and cataplexy were treated with gamma-hydroxybutyrate $(G H B)$ given at night and tailored to achieve as continuous a night's sleep as possible. The dosage usually' consisted of 1.5-2.25 gm orally at bedtime and then one or two further 1.0$1.5 \mathrm{gm}$ doses with awakenings during the night, and totaled about $50 \mathrm{mg} / \mathrm{kg}$. Apart from one patient who took only the bedtime dose, the subjective quality of night sleep improved in all patients and the

RÉSUMÉ: Seize malades qui présentaient des épisodes de narcolepsie et de cataplexie ont été traités la nuit avec hydroxybutyrate-gamma. Il était dosé pour donner un sommeil nocturne le plus continuel possible. Le dosage normal était de 1.5-2.25 gm. par voie orale avant le coucher suivi par un ou deux autres dosages de 1.0-1.5 gm. pour les réveils nocturnes. Le dosage total était approximativement de $50 \mathrm{mg} /$ $\mathrm{kg}$. Le sommeil nocturne de tous les malades s'est amélioré, sauf pour un seul number of irresistable daytime attacks of sleep and cataplexy substantially diminished. Some residual daytime drowsiness remained and this usually responded well to low doses of methylphenidate. Improvement has been maintained for up to 20 months without the development of tolerance. Two patients experienced adverse side effects necessitating withdrawal of GHB treatment, but no serious toxic effects have occurred.

qui ne prenait que le dosage avant le coucher, et le nombre d'épisodes de sommeil diurne irrésistible et de cataplexie étaient très diminués. Une somnolence résiduelle et diurne persistait, ce qui habituellement répondait bien au dosage minime de methulphenidate. L'amélioration clinique a été maintenue jusqu'à 20 mois sans l'apparition de tolérance. Deux malades ont eu des effets secondaires qui nécessitaient l'arrêt du traitement, mais aucun effet toxique sérieux n'a eu lieu.
From the Division of Neurology, Ottawa General Hospital and University of Ottawa, and the Department of Psychiatry, Sunnybrook Medical Centre and University of Toronto, Canada.

Reprints requests to: Dr. Broughton, Department of Medicine (Neurology), Ottawa General Hospital, Ottawa, Canada, KIN 5C8.

\section{INTRODUCTION}

The prevalence of narcolepsy has been shown in epidemiological studies to be about $0.1 \%$ (Roth, 1962; Dement et al., 1973). Therefore it is more frequent than a number of much better known chronic neurological conditions, such as multiple sclerosis. Moreover, as it generally begins in young adulthood and remains for the patients' lifetime, and as it has marked detrimental effects involving employment, education, recreation, interpersonal relations, driving, accidents in general and other parameters of everyday life (Broughton and Ghanem, 1976), the condition can be truly debilitating. The investigation of narcolepsy by modern polysomnographic techniques has shown that of the classical so-called 'tetrad' of Daly and Yoss (1960), the auxillary symptoms (i.e. those other than sleep attacks) of cataplexy, sleep paralysis, and vivid hypnogogic hallucinations are all based upon abnormal rapideye-movement (REM) sleep mechanisms, and that the sleep attacks of patients with narcolepsy-cataplexy begin in REM sleep in $50-100 \%$ of attacks (Broughton, 1971; Zarcone, 1973), depending upon the author. These findings have led to the addition of drugs which suppress REM sleep, i.e. tricyclic antidepressants (imipramine, chlorimipramine, and desipramine) or less frequently MAO inhibitors (phenelzine) to traditional stimulant medication, usually methylphenidate. The antidepressants have been largely effective in reducing the auxillary symptoms of cataplexy, sleep paralysis and hypnogogic hallucinations, whereas methylphenidate has been most useful for the sleep attacks and for the more or less continuous daytime drowsiness 
presented by these patients (Zarcone, 1973). Despite these therapeutic improvements over stimulants alone, the treatment of narcolepsy still remains unsatisfactory. In many patients control of symptoms is far from complete. Others show undesirable side effects discussed later.

This situation led us to use a somewhat different therapeutic strategy. Rather than concentrating upon suppressing the daytime symptoms, we decided to attempt to improve their night-time sleep, which is characterized by early or direct entry into REM sleep (Rechtschaffen et al., 1963), much sleep fragmentation with particular inability to sustain periods of REM sleep (Montplaisir, 1976), and by other features, in the hope that daytime pressure for sleep-related symptoms would be reduced. There were at least two reasons for suggesting that disturbed nocturnal sleep might be central to the physiopathogenesis of narcolepsy with cataplexy. First, prolonged periods of sleep deprivation or of irregular sleep precede the onset of major symptoms of the disease in $50-75 \%$ of patients (Mitchell and Dement, 1968; Broughton and Ghanem, 1976) with idiopathic narcolepsy. Secondly, narcoleptics are known to be very vulnerable to the effects of shift work, and therefore to alteration in their circadian sleep-wakefulness rhythms. Such disturbances regularly aggravate their symptoms (Broughton, 1971).

We chose the sodium salt of gammahydroxybutyrate (GHB) (Laborit, 1964; Muzard and Laborit, 1977; Snead, 1977) in our attempt to "normalize" the nocturnal sleep patterns of patients with narcolepsy and cataplexy. This short chain fatty acid is a normal constituent of the human nervous system (Doherty and Roth, 1976). It possesses definite hypnotic properties. But in distinction to the commonly used synthetic hypnotics, it promotes sleep which more closely approximates that of normal sleep than do other hypnotics, since it does not inhibit either REM or NREM sleep (Jouvet et al., 1961; Matsuzaki et al., 1964; Mamelak et al., 1977; Muzard and Laborit, 1977). GHB also has an additional possible advantage over the synthetic hypno- tics in that animal studies had failed to demonstrate the development of tolerance to its hypnotic effects with prolonged use (Vickers, 1969). To date we have treated 16 patients with nocturnal GHB. Preliminary results in our first four patients have already been reported (Broughton and Mamelak, 1976).

\section{PATIENTS AND METHODS}

The sixteen patients, 8 men and 8 women, ranged in age from 21-58 years (Mean $=41.8$, s.d. 13.6; Table 1). All had histories of diurnal drowsiness, irresistible sleep attacks, and cataplexy. The other main symptoms of the disease were also present in individual patients to varying degrees. In four patients, the symptoms had been particularly debilitating in spite of treatment with the usual combination of methylphenidate and tricyclic antidepressant drugs. The entire protocol and the investigative nature of the study were carefully explained to each patient and consent forms were signed. In all patients, a sleep onset REM period was observed during at least one daytime polysomnographic recording. Before starting treatment with GHB, all previous drug treatment for narcolepsy was discontinued for at least 14 days. A history and physical were performed and the following laboratory tests completed: hemogram, liver survey, renal survey, chest $\mathrm{x}$-ray, EEG and ECG. Each patient was also given a psychological examination and the Minnesota Multiphasic Personality Inventory.

Polysomnographic assessment of sleep-waking patterns was done for at least 48 continuous hours in the baseline state and then at regular intervals while on GHB. In the Ottawa patients $(\mathrm{N}=9)$ recordings were performed without hospitalization using a portable 4-channel apparatus which permitted the monitoring of patients at their habitual activity levels in the normal home or work environment. In the Toronto studies, patients $(\mathrm{N}=7)$ were hospitalized during the recording periods and the usual polysomnographic techniques were employed. None of the patients had histories of loud snoring or of the peculiar gutteral inspiratory snoring which characterizes sleep apnea.
Moreover, this symptom was formally excluded by respiratory monitoring (nasal thermistor and abdominal belt transducer) in Toronto studies, where sufficient recording channels made this possible. The Stanford Sleepiness Scale (Hoddes et al., 1973), which is a self-assessed 1 to 7 scale of alertness, was filled in every 30 minutes over at least 3 consecutive days during wakefulness in the pre-GHB baseline period, and during reassessments while on the drug.

Treatment with GHB was started once the initial baseline data was gathered. The treatment schedule was tailored to achieve as continuous a night's sleep as possible. The patient's body weight and his polysomnographic response to GHB were used as guides. Since each sleep inducing oral dose of GHB lasts only two or three hours (Mamelak et al., 1977) - indeed the substance is only detectable in blood that long (Helrich et al., 1964) -and because our aim was to maximize the duration of sleep produced by the drug while minimizing its anaesthetic effects, multiple doses were used. The usual initial dose was $1.5-2.25 \mathrm{gm}(10-15 \mathrm{ml}) \mathrm{hs}$, followed by further multiple 1.0-1.5 gm doses during the night with each major reawakening, if at least 2.5 hours had passed since the previous dose. Usually only 2 or 3 doses per night were necessary. Each dose was about $30 \mathrm{mg} / \mathrm{kg}$, but the total quantity of GHB given each night ranged from 3.75 to 6.25 gms, corresponding to approximately $50 \mathrm{mg} / \mathrm{kg}$.

After seven to ten nights on GHB, the 48 hour polysomnographic recording was repeated with the patient continuing to use the drug according to the optimal dose schedule previously established. Major reassessments were again performed after at least one month, six months and 12 months on GHB. On each of these occasions, the clinical effects of the treatment were assessed, the blood and urine studies, chest $x$-ray and ECG were repeated, and any adverse reactions to the drug noted and investigated.

GHB was obtained from Laboratoire Egic in France, who market this drug in syrup form under the trade 
TABLE 1.

Patients' Symptoms, Previous Treatment and Response to Nocturnal Gamma Hydroxy Butyrate

\begin{tabular}{|c|c|c|c|c|c|c|c|c|c|}
\hline Patient & Age & Sex & $\begin{array}{c}\text { Major } \\
\text { Symptoms } \\
\end{array}$ & $\begin{array}{l}\text { Duration } \\
\text { of Illness }\end{array}$ & $\begin{array}{c}\text { Previous } \\
\text { Medication }\end{array}$ & $\begin{array}{c}\text { Usual GHB } \\
\text { Dosage } \\
\text { gm/night }\end{array}$ & Response & Toxicity & Comments \\
\hline 1 & 21 & $F$ & $\mathrm{~N}, \mathrm{SP}, \mathrm{HH}$ rare $\mathrm{C}$ & 6 years & diazepam hs & 3.0 & +++ & none & - \\
\hline 2 & 22 & $M$ & N,C,SP,HH & 4 years & diazepam sed ${ }^{n}$ & 3.75 & + & none & - \\
\hline 3 & 23 & F & $\mathrm{N}, \mathrm{C}, \mathrm{SP}, \mathrm{HH}$ & 3 years & none & 3.75 & +++ & none & - \\
\hline 4 & 25 & F & $\mathrm{N}, \mathrm{C}, \mathrm{SP}$ & 5 years & benzedrine & 2.25 & 0 & none & Took only hs dose \\
\hline 5 & 32 & F & $\mathrm{N}, \mathrm{C}, \mathrm{SP}, \mathrm{HH}$ & 14 years & dexedrine & 5.25 & +++ & none & Sister of pat. 4 \\
\hline 6 & 38 & F & $\mathrm{N}, \mathrm{C}, \mathrm{SP}, \mathrm{HH}$ & 15 years & $\begin{array}{l}\text { dexedrine } \\
\text { methylphenidate } \\
\text { chlorimipramine }\end{array}$ & 3.75 & +++ & 'none & Old gastrectomy \\
\hline 7 & 40 & $\mathbf{M}$ & $\mathrm{N}, \mathrm{C}, \mathrm{SP}, \mathrm{HH}$ & 28 years & $\begin{array}{l}\text { dexedrine } \\
\text { methylphenidate } \\
\text { imipramine } \\
\text { chlorimipramine } \\
\text { phenelzine }\end{array}$ & 4.50 & +++ & none & - \\
\hline 8 & 43 & $\mathrm{~F}$ & $\mathrm{~N}, \mathrm{C}, \mathrm{SP}, \mathrm{HH}$ & 13 years & $\begin{array}{l}\text { dexedrine } \\
\text { methylphenidate } \\
\text { imipramine } \\
\text { chlorimipramine } \\
\text { phenelzine } \\
\text { phenytoin } \\
\text { carbamazepine }\end{array}$ & 4.50 & ++ & $\begin{array}{c}\text { abdominal pain } \\
\text { muscle weak- } \\
\text { ness }\end{array}$ & $\begin{array}{l}\text { No evidence for } \\
\text { epilepsy }\end{array}$ \\
\hline 9 & 45 & $\mathrm{~F}$ & $\mathrm{~N}, \mathrm{C}, \mathrm{SP}$ & 23 years & dexedrine & 6.25 & + & none & 一 \\
\hline 10 & 45 & $\mathbf{M}$ & $\mathrm{N}, \mathrm{C}, \mathrm{SP}, \mathrm{HH}$ & 3 years & methylphenidate & 4.50 & +++ & $\begin{array}{c}\text { temporary } \\
\text { muscle weakness }\end{array}$ & - \\
\hline 11 & 52 & M & $\mathrm{N}, \mathrm{C}, \mathrm{SP}$ & 14 years & desoxyn & 3.75 & +++ & none & $\begin{array}{l}\text { Impotence on } \\
\text { previous } R\end{array}$ \\
\hline 12 & 55 & M & $\mathrm{N}, \mathrm{C}$ & 30 years & methylphenidate & 3.75 & +++ & none & - \\
\hline 13 & 56 & M & $\mathrm{N}, \mathrm{C}, \mathrm{SP}$ & 31 years & methylphenidate & 3.75 & +++ & $\begin{array}{l}\text { dysthesiae } \\
\text { left hand }\end{array}$ & $\begin{array}{l}\text { Post-traumatic } \\
\text { epilepsy }\end{array}$ \\
\hline 14 & 57 & $\mathbf{M}$ & $\mathrm{N}, \mathrm{C}$ & 43 years & ephedrine & 4.50 & +++ & none & - \\
\hline 15 & 57 & $\mathbf{M}$ & $\mathrm{N}, \mathrm{C}, \mathrm{SP}, \mathrm{HH}$ & 33 years & dexedrine & 5.25 & +++ & none & - \\
\hline 16 & 57 & F & $\mathrm{N}, \mathrm{C}, \mathrm{SP}, \mathrm{HH}$ & 37 years & $\begin{array}{l}\text { dexedrine } \\
\text { methylphenidate } \\
\text { impramine } \\
\text { chlorimipramine }\end{array}$ & 3.75 & +++ & none & - \\
\hline
\end{tabular}

$0=$ no effect; $+/-=0-20 \%$ improvement $+=20-40 \%$ improvement

$++=40-70 \%$ improvement $+++=$ over $75 \%$ reduction of symptoms from baseline

$\mathrm{N}=$ irrisistible sleep attacks; $\mathrm{C}=$ cataplexy; $\mathrm{SP}=$ sleep paralysis; $\mathrm{HH}=$ vivid hypnagogic hallucinations

name "GammaOH". We found it best to dilute the syrup in milk or juice, in order to reduce the gastrointestinal upset caused in some patients when the drug was given in undiluted form. Dilution also retarded GHB's rate of absorption somewhat, so that sleep induction was experienced as gradual and more normal.

\section{RESULTS}

We wish to report our clinical observations here. The polysomnograpic and Stanford Sleep Scale data and our psychological findings are still being analyzed and will be presented in a future publication. The patient and clinical results are summarized in Table 1.

\section{CLINICAL RESPONSE}

The ameliorating effects of $\mathrm{GHB}$ on the major daytime symptoms of narcolepsy appeared gradually. By comparison, the subjective quality of night-time sleep improved very rapidly. Over the first 2 to 5 nights, nocturnal sleep became less restless and nightmares, hallucinations, and attacks of sleep paralysis vanished. Some episodes of intense awakenings at about 2-3 hours after taking the initial doses were encountered. These appeared to represent a drug-related rebound phenomenon. Although dreaming continued, it lost its frightening qualities. All patients found it easier to stay awake during the day and noted that after a number of weeks, the irresistible pressure for diurnal sleep and the attacks of cataplexy virtually disappeared. When cataplexy did occur, the attacks were 
usually relatively brief, less intense, and tended to occur late in the day when the individual was very tired. Most patients said that they were much more refreshed after their night sleep and were better able to cope during the daytime. Despite these beneficial effects on the major symptoms of the disease and on the subjective quality of sleep, many patients continued to feel somewhat tired and drowsy during the day. We then added 5 to $10 \mathrm{mg}$ of methylphenidate three times a day to their treatment regimen. It was taken on an empty stomach before breakfast and lunch, and then again in the midafternoon. With this addition, the daytime drowsiness and fatique became minimal.

Our patients generally reported that sleep gradually consolidated into a seven to eight hour period. One patient, however, reported that if she slept through the night and failed to take her second dose of GHB, the attacks of narcolepsy and cataplexy recurred on the following day. The single patient (No. 4) who failed to respond at all to GHB treatement, turned out to be taking only the single h.s. dose of the drug. Some patients on their own tried to discontinue GHB treatment and to rely on methylphenidate alone, but they noticed recurrence of their symptoms after a few days.

In patients responding to $\mathrm{GHB}$, the improvement was maintained throughout the trial period. The development of tolerance requiring increasing doses for the same clinical effect on night sleep, sleep attacks or cataplexy has not been encountered. As with traditional forms of treatment, it was found that having patients keep regular hours of retiring and of morning awakening was important for optimal therapeutic effectiveness. At the time of writing, one patient has been on GHB nightly for nearly two years, three others have been on it for over a year, and the remainder have been on it for three months to a year.

\section{SIDE EFFECTS}

There have been very few adverse clinical effects with this treatment and no abnormal laboratory findings.
Minor side effects of GHB have been seen for the first few days in a number of patients which consisted of a "thick head", ocular discomfort, and other apparent hangover effects, but these were rare after one week. Impotence or reduced libido has never been encountered. We decided to discontinue the drug in two patients. One (patient No. 8) complained of nonspecific abdominal pain while using GHB plus muscular weakness in the morning, to the point where she found it difficult to initiate movement. Both of these symptoms disappeared when the drug was stopped. A second patient (No. 13), a male with a posttraumatic narcolepsy and cataplexy, experienced disturbing left arm dysthesiae. He had previously had similar symptoms after the initial head injury. A third patient (No. 10) complained of muscular weakness in the morning, also limited to his left arm. This man had suffered a neck injury a few weeks before starting GHB and his left arm was weak following the event. It had gradually been recovering, but the weakness recurred when he started using the drug. Because his narcolepsy improved so dramatically on GHB, we continued to use the drug in spite of the effect on his arm and the weakness gradually disappeared over a few weeks.

Several patients have also mentioned that GHB caused urinary urgency. On one occasion, enuresis occurred in a patient about an hour after the drug had been given. On the whole, however, urgency has not been a serious problem and our patients report that they void no more frequently during the night on GHB than they did before starting the drug. Another complaint from a number of patients was that GHB produced a dream-like confusional state which could be unpleasant and frightening. This happened when the drug was taken before they were ready for sleep, or when they fought against its sleep promoting actions. This phenomenon is rare if patients cooperate with the drug's hypnotic effects and use it at the minimal dose required for sleep induction and maintenance. No other side-effects were encountered and, in sum, most patients felt they had fewer side-effects and substantially better relief from symptoms on GHB than on any previous medication.

\section{DISCUSSION}

The salient finding in this study was the marked clinical improvement produced by nocturnal GHB in patients with narcolepsy-cataplexy. This action was coupled with a paucity of adverse clinical or laboratory findings. When GHB was used at night, and supplemented with small doses of methylphenidate during the day, all the major symptoms of narcolepsy were markedly reduced. The project has involved detailed study of a limited number of patients over substantial periods of time. It is not a double-blind controlled design. But, the therapeutic effects on patients previously uncontrolled by the more traditional drug regimens and the rapid deterioration in those who discontinued the use of the drug on their own for several nights leave little doubt about the compound's effectiveness.

The use of GHB for the treatment of this disease has a number of clear advantages over more conventional therapies. As mentioned, the latter usually use substantial doses of stimulants such as methylphenidate or d-amphetamine, alone, or in combination with tricyclic antidepressants such as imipramine or chlorimipramine. The stimulants, however, cause irritability and anxiety in many patients and more serious side effects in others. One of our patients previously had had a gastrectomy for ulcers attributed to stimulant medication. The antidepressant drugs, on the other hand, may cause dry mouth, sweating, and impotence in males (Zarcone, 1973; Dement et al., 1976). The stimulant-antidepressant combination does not consolidate sleep, and in fact may even further disrupt it. Moreover, tolerance develops in time both to the level of stimulants generally employed and to antidepressants so that after a number of months, many patients complain that their symptoms are again every bit as troublesome as they were to begin with. None of these problems occur with GHB. Nocturnal sleep was restful 
and sustained and patients awoke alert and well rested. There were few side effects and, specifically, no impotence or reduced libido. Tolerance to the drug's actions did not develop, nor did it develop to the relatively small doses of methylphenidate taken during the day, when taken in combination with nocturnal GHB.

Some of the therapeutic and sideeffects of GHB may be related to its influence on motor mechanisms. It is known to inhibit muscle tone (Vickers, 1969) and to block the H-reflex response (Uspenskii, 1965; Muzard and Laborit, 1977). In narcoleptics, as well as in normals, the H-reflex response can be abolished by GHB and remains somewhat attenuated for some time after the patient awakens (Mamelak, Sowden and Caruso, unpublished observations). The latter may be due to residual effects of small quantities of unmetabolized drug. This effect may account for the weakness experienced by two of our patients upon arising in the morning. The sustained hypotonia throughout sleep may be as important as any effect on sleep patterns in the subjective feeling of having had a deep refreshing night's sleep. As far as the urinary urgency is concerned, this has been noted by some patients even if they empty their bladders before bedtime, but it has not proved to be a treatment problem. It is intriguing to speculate, however, that the combination of profound sleep and enuresis observed in childhood might be related to a higher brain GHB concentration present in the early years of life.

GHB's mechanisms of action in the treatment of the major symptoms of narcolepsy remains uncertain. It has been known for many years that hypnotic drugs can be helpful for at least some narcoleptic patients (Daniels, 1934; Zarcone, 1973). Recent studies have shown that narcoleptics do not sleep more in the 24-hour period than normal individuals (Hishikawa et al., 1976). Thus, consolidating the fragmented sleep of these patients into a seven or eight hour period by means of hypnotic drugs should theorectically decrease the need for daytime sleep. Perhaps this is how ordinary hypnotics benefit these patients. But, it must be noted that some of our narcoleptic patients slept reasonably soundly at night and that in these patients nocturnal sleep in fact became more fragmented after starting GHB, because they had to wake up for the second dose. If they failed to take it their symptoms recurred. Furthermore, a preliminary review of our polysomnographic data indicates that GHB did not substantially increase the overall duration of sleep in the eight hour night-time period. GHB, then, likely has more specific actions on sleep mechanisms than simply increasing the duration of nocturnal sleep or its gross continuity. As yet, basic neurochemical studies offer few real insights into the drug's mechanism of action, although it has been shown that GHB may be derived from GABA (Roth and Giarman, 1969), and may act as a GABA agonist (Roth et al., 1977) and that it alters dopamine (Roth and Suhr, 1970), serotonin (Spano et al., 1970), and acetylcholine (de la Mora et al., 1970) metabolism. The last three, at least, have been implicated in sleep control mechanisms (Jasper and Koyama, 1969; Jouvet, 1969; Cordeau, 1970; Morgane and Stern, 1972).

Whatever its precise mode of action, this essentially non-toxic constituent of the normal brain does appear to have important clinical therapeutic effects even in otherwise refractory cases of narcolepsy. Moreover, its effectiveness, when given in the nighttime period, adds strong support for the postulated importance of the quality of night sleep in the genesis of daytime sleep attacks and cataplexy. It gives promise that GHB itself or similar substances (we have also used gamma-butylactone sucessfully) may lead to substantial improvement in the control of this debilitating neurological disease. The main disadvantage at present is its relatively short duration of action. It is hoped that this might be extended by use of slow release capsules or another approach in order to produce a sustained 7-8 hour overnight effect.

\section{ACKNOWLEDGEMENTS}

We thank Laboratoire Egıc, Paris for supplyıng the gamma-hydroxybutyrate and the Health Protection Branch. Health and Welfare Canada (Dr. T. Da Silva) for giving clearance to import the substance for the clinical trial. We also thank Tom Healey, Jagdish Maru, Olga Stokan, Vicky Caruso and Keith Stewart for their technical assistance with this project. The project has been supported by the Medical Research Council of Canada.

\section{REFERENCES}

BROUGHTON, R. (1971). Neurology and sleep research. Can. Psychiatr. Assoc. J., 16, 283292.

BROUGHTON, R. and GHANEM, Q. (1976). A study of the impact of compound narcolepsy on the life of the patient. In Narcolepsy, edited by "C. Guilleminault, W. C. Dement and P. Passouant, pp. 201220. Spectrum: New York.

BROUGHTON, $R$. and MAMELAK, $M$ (1976). Gamma-hydroxybutyrate in the treatment of compound narcolepsy: A preliminary report. In Narcolepsy, edited by C. Guilleminault, W. C. Dement and P. Passouant, pp. 659-667. Spectrum: New York

CORDEAU, J. P. (1970). Monoamines in the physiology of sleep and waking. In L-Dopa and Parkinsonism, edited by $A$. Barbeau and F. H. McDowell, pp. 369-383. Davis: Philadelphia.

DALY, D. D. and YOSS, R. E. (1960). Narcolepsy. Med. Clin. North Am., 44, $953-$ 968.

DANIELS, L. (1934). Narcolepsy. Medicine (Baltimore), 13, 1-22.

DE LA MORA, M. and TAPIA, R. (1970). Neurochemical and physiological aspects of gamma-hydroxy-butyric acid as a natural soporific. Ann. Instit. Boil. Auton. Mex., I, 41-53.

DEMENT, W. C., CARSKADON, M. A., GUILLEMINAULT, C., and ZARCONE, V. P. (1976). Narcolepsy: diagnosis and treatment. Primary Care, 3, 609-623.

DEMENT, W. C., CARSKADON, M. and LEY, R. (1973). The prevalence of narcolepsy, II. Sleep Research, 2, 147.

DOHERTY, J. D. and ROTH, R. H. (1976). Identification of gamma-hydroxybutyric acid as an endogenous metabolite present in monkey and human brain. Fed. Proc., 35, 270.

HELRICH, M.. McASLAN, T. C., SKOLNIK, S., BESSMAN, S. P. (1964). Correlation of blood levels of 4-hydroxybutyrate with state of consciousness. Anaethesiology. 25, 771775.

HISKIKAWA, Y., WAKAMATSU, H. FURUYA, E., SUGITA. Y., MASAOKA, S., KANEDA, H., SATO, M.. NAN'NO, H., and KANEKO.Z. (1976). Sleep satiation in narcoleptic patients. Electroencephalogr. Clin. Neurophysiol., 41, 1-18.

HODDES, E.. ZARCONE, V., SMYTHE, H. PHILLIP, S., and DEMEIT, W. (1973) Quantification of sleepiness: A new approach. Psychophysiology, 10, 431-436. 
JASPER, H. and KOYAMA, I. (1969). Rate of release of amino acids from cerebral cortex in the cat as affected by brainstem and thalamic stimulation. Can. J. Physiol. Pharmacol., 47, 889-905.

JOUVET, M. (1969). Biogenic amines and the states of sleep. Science, 163, 32-41.

JOUVET, M., CIER, A., MOUNIER, D., VALATX, J. L. (1961). Effets du 4butyrolactone et du 4-hydroxybutyrate de sodium sur l'EEG et le comportement du chat. C. R. Soc. Biol. (Paris), 155, 13131316.

LABORIT, H. (1964). Sodium-4-hydroxybutyrate. Int. J. Neuropharmacol., 3, 433-451.

MAMELAK, M., ESCRIU, J. M. and STOKAN, O. (1977). The effects of gammahydroxybutyrate on sleep. Biol. Psychiatry, 12, 273-288.

MATSUZAKI, M., TAKAGI, $H$. and TOKIZANE, T. (1964). Paradoxical phase of sleep: Its artificial induction in the cat by sodium butyrate. Science, 146, 1328-1329.

MITCHELL, S. A. and DEMENT, W. C. (1968). Narcolepsy syndromes: antecedent, contiguous and concomitant nocturnal sleep disordering and deprivation. Psychophysiology, 4, 398.
MONTPLAISIR, J. (1976). Disturbed nocturnal sleep. In Narcolepsy, edited by $C$. Guilleminault, W. C. Dement and P. Passouant, pp. 43-56. Spectrum: New York.

MORGANE, P. J. and STERN, W. C. (1972). Relationship of sleep to neuroanatomical circuits biochemistry, and behavior. Ann. N.Y. Acad. Sci., 193, 95-111.

MUZARD, J. P. and LABORIT, H. (1977). Gammahydroxybutyrate. In Psychotherapeutic Drugs, Part II, edited by E. Usdin and I. Forrest. Marcel Dekker: New York.

RECHTSCHAFFEN, A., WOLPERT, E., DEMENT, W., MITCHELL, S. and FISHER, C. (1963). Nocturnal sleep of narcoleptics. Electroencephalogr. Clin. Neurophysiol., 15, 599-609.

ROTH, B. (1962). Narcolepsie und Hypersomnie. V.E.B. Verlag Volk und Gesundheit: Berlin, p. 428.

ROTH, R. H. and GIARMAN, N. J. (1969). Conversion in vivo of gamma-aminobutyric to gamma-hydroxybutyric acid in the rat. Biochem. Pharmacol., 18, 147-250.

ROTH, R. H. and SUHR, Y. (1970). Mechanism of the gamma-hydroxybutyrate induced increase in brain dopamine and its relationships to "sleep". Biochem. Pharmacol., 19, 3001, 3012.
ROTH, R. H., NOWYCKY, M. C., WALTERS, J. R. and MORGENROTH, V. H. (1977). Gammahydroxybutyrate: Effects on Nonstriated Dopaminergic Neurons. Adv. Biochem. Psychopharmacol., $16,483-488$.

SNEAD, O. C. (1977). Gammahydroxybutyrate. Life Sci., 20, 1935-1944.

SPANO, P., NEFF, N. and COSTA, E. (1970). Effect of gammahydroxybutyrate on the synthesis rate of brain amines. Trans. Am. Soc. Neurochem., 1, 69.

USPENSKII, A. E. (1965). Effect of sodium salt of gamma-hydroxybutyric acid on synaptic transmission in the spinal cord. Fed. Proc., 24, 673-675.

VICKERS, M.D. (1969). Gamma-hydroxybutyric acid. Int. Anaesthesiol. Clin., 7, 75-89.

YAMADA, Y., YAMAMOTO, J., FUJIKI, A., HISHIKAWA, $Y$. and KANEDO, $Z$. (1967). Effect of butyrolactone and gammahydroxybutyrate in the EEG and sleep cycle in man. Electroencephalogr. Clin. Neurophysio., 22, 558-562.

ZARCONE, V. (1973). Narcolepsy. N. Engl. J. Med., 288, 1156-1166. 